\title{
Estradiol Modulates Membrane-Linked ATPases, Antioxidant Enzymes, Membrane Fluidity, Lipid Peroxidation, and Lipofuscin in Aged Rat Liver
}

\author{
Pardeep Kumar, R. K. Kale, and Najma Zaheer Baquer \\ School of Life Sciences, Jawaharlal Nehru University, 110067 New Delhi, India \\ Correspondence should be addressed to Najma Zaheer Baquer, epardeep@gmail.com
}

Received 25 January 2011; Revised 11 May 2011; Accepted 8 July 2011

Academic Editor: Michal Masternak

Copyright ( $) 2011$ Pardeep Kumar et al. This is an open access article distributed under the Creative Commons Attribution License, which permits unrestricted use, distribution, and reproduction in any medium, provided the original work is properly cited.

\begin{abstract}
Free radical production and oxidative stress are known to increase in liver during aging, and may contribute to the oxidative damage. These changes increase during menopausal condition in females when the level of estradiol is decreased. The objective of this study was to observe the changes in activities of membrane linked ATPases $\left(\mathrm{Na}^{+} \mathrm{K}^{+}\right.$ATPase, $\mathrm{Ca}^{2+}$ ATPase), antioxidant enzymes (superoxide dismutase, glutathione-S-transferase), lipid peroxidation levels, lipofuscin content and membrane fluidity occurring in livers of female rats of 3,12 and 24 months age groups, and to see whether these changes are restored to 3 months control levels rats after exogenous administration of 17- $\beta$-estradiol (E2). The aged rats ( 12 and 24 months) were given subcutaneous injection of E2 $(0.1 \mu \mathrm{g} / \mathrm{g}$ body weight $)$ daily for one month. The results obtained in the present work revealed that normal aging was associated with significant decrease in the activities of membrane linked ATPases, antioxidant enzymes, membrane fluidity and an increase in lipid peroxidation and lipofuscin content in livers of aging female rats. The present study showed that E2 treatment reversed the changes to normal levels. E2 treatment may be beneficial in preventing some of the age related changes in the liver by increasing antioxidant defenses.
\end{abstract}

\section{Introduction}

Free radical production and oxidative stress are known to increase in liver during aging and may contribute to the oxidative damage, which plays an important role in the aging process [1]. Oxidative stress has been implicated in the pathogenesis of several alterations due to menopause and can arise through the increased production of lipid peroxides and/or a deficiency of antioxidant defense $[2,3]$.

Recently, there has been a growing interest in the actions and functions of the estrogen replacement therapy and steroid hormone estrogens (17- $\beta$-estradiol, E2) important role in the progression of chronic hepatic diseases and synaptic plasticity $[4,5]$. Moorthy et al. [6] reported that older women might also benefit from the protective effects of hormone replacement therapy (HRT) that uses a relatively lower concentration of hormones. E2 could enhance antioxidant and antiapoptotic activity in hepatic fibrosis in rats $[7,8]$.
Morphofunctional studies suggest that the liver, compared with other organs, ages fairly well [9]. Superoxide dismutase (SOD), which decreased in rat liver, brain, heart, kidney, and uterus $[10,11]$ during aging, constitutes an important defense system to clear up the detrimental reactive oxygen species (ROS) in vivo [2]. Glutathione S-transferases (GST) belong to a group of multigene and multifunctional detoxification enzymes, which defend cells against a wide variety of toxic insults from chemicals, metabolites, and oxidative stress [12]. GST decreased with aging in liver [13], brain [14], and heart [11].

Oxidative stress is postulated to be one of the most important mechanisms behind age-related decrease in SOD and GST activities in aging rats $[15,16]$. Accordingly, many studies in the past attempted to clarify how these enzyme activities are altered during aging (for review, see $[2,17]$ ).

$\mathrm{Na}^{+} \mathrm{K}^{+}$ATPase and $\mathrm{Ca}^{2+}$ ATPase are transmembranous enzymes that play an important role in maintaining ionic homeostasis and physiologic function of the liver $[18,19]$. 
Decreased $\mathrm{Na}^{+} \mathrm{K}^{+}$ATPase and $\mathrm{Ca}^{2+}$ ATPase activities in liver of aging animals affect the signal transduction pathway and cellular functions, suggested as a contributing factor in the development of age-related disorders with increase in the content of lipid peroxidation [20,21].

Free radicals oxidize polyunsaturated fatty acid leading to the fact that membrane fluidity decreases with aging, impairing the crucial membrane functions of transport and permeability [22, 23]. Malondialdehyde (MDA) is one of the end products in the lipid peroxidation process which leads to increase in phospholipids rigidity [24]. Lipofuscin is an autofluorescent pigment that accumulates inside aging tissue due to increased oxidative stress which represents an end product of oxidative degradation of lipids [25, 26]. Kumar et al. $[27,28]$ had shown that lipofuscin is a peroxidation product, and its formation appears to be proportional to the occurrence of lipid peroxidation.

The aim of the present study was to investigate the antiaging and protective potential of lower doses of E2 than HRT levels treatment on activities of membrane-linked ATPases $\left(\mathrm{Na}^{+} \mathrm{K}^{+}\right.$ATPase, $\mathrm{Ca}^{2+}$ ATPase), antioxidant enzymes (SOD, GST), lipid peroxidation levels, lipofuscin content, and membrane fluidity in the liver of aging female rats.

\section{Materials and Methods}

2.1. Animals. Female albino rats of the Wistar strain of different ages namely 3,12 , and 24 months $(n=8$ for each group) were used for all the experiments. Animals were maintained in the animal house facility of Jawaharlal Nehru University (JNU), New Delhi, India, at a constant temperature of $25^{\circ} \mathrm{C}$, humidity of $55 \%$ at 8:00 to $20: 00 \mathrm{~h}$ light, and 20:00 to $8: 00 \mathrm{~h}$ dark cycle. The animals were fed standard chow (Hindustan Lever Ltd., India) and given tap water ad libitum until treatment or time of sacrifice. All the animal procedures were approved by the Institutional Animal Ethical Committee (IAEC) of Jawaharlal Nehru University, New Delhi, India

2.2. Hormone Administration. The aged rats (12 and 24 months old) ( $n=8$ for each group) were given subcutaneous injection of $17-\beta$-estradiol $(0.1 \mu \mathrm{g} / \mathrm{g}$ body weight $)$ daily for one month. E2 was dissolved in propylene glycol in appropriate concentrations $[6,29]$. Control animals received an equal volume of vehicle. There was no treatment on the day of the sacrifice. After 30 days of hormone treatment, experimental animals of all the groups were sacrificed and livers were isolated for further study.

\subsection{Preparation of Homogenates and Subcellular Fractions.} Animals were sacrificed by cervical dislocation. Livers were rapidly excised and washed with chilled normal saline. The homogenates and subcellular fractions were prepared as described earlier; the pellet obtained at 12,000 g containing mitochondria and the supernatant fractions were used for enzyme assays $[6,30]$. The pellet was used for determining $\mathrm{Na}^{+} \mathrm{K}^{+}$ATPase and $\mathrm{Ca}^{2+}$ ATPase activities and membrane fluidity. Whole homogenates were used for measurement of lipofuscin and lipid peroxidation. Supernatant fraction was used for estimation of GST and SOD activities.

\subsection{Measurements of Enzymes}

2.4.1. Assay of SOD (EC: 1.15.1.1). The activity of SOD was determined by the method of S. Marklund and G. Marklund [31], using inhibition of pyrogallol autooxidation at $\mathrm{Ph}$ 8.0. The specific activity of SOD is expressed as units per $\mathrm{mg}$ protein per minute.

2.4.2. Assay of GST (EC: 2.5.1.1.8). The specific activity of cytosolic GST was determined spectrophotometrically at $37^{\circ} \mathrm{C}$ as described by Gupta et al. [32]. The reaction mixture $(1 \mathrm{~mL})$ contained final concentration of $0.1 \mathrm{M}$ phosphate buffer ( $\mathrm{pH} 6.5$ ), $1 \mathrm{mM} \mathrm{CDNB}$ in 95\% ethanol, and $1 \mathrm{mM}$ GSH and was incubated at $37^{\circ} \mathrm{C}$ for $5 \mathrm{~min}$. The specific activity of GST is expressed in terms of micromoles of GSHCDNB conjugate formed $/ \mathrm{min} / \mathrm{mg}$ protein.

2.4.3. Assay of $\mathrm{Na}^{+} \mathrm{K}^{+}$ATPase (E.C: $3 \cdot 6 \cdot 1.37$ ). $\mathrm{Na}^{+} \mathrm{K}^{+}$ATPase activity was measured in the pellet according to the method of Mayanil et al. [33]. The enzyme activity was calculated as the difference of the activity between total ATPase and $\mathrm{Mg}^{2+}$ ATPase. The specific activity of the enzyme is expressed as $\mu \mathrm{mol} \mathrm{Pi}$ released/mg protein/min.

2.4.4. Assay of $\mathrm{Ca}^{2+}$ ATPase (EC: $3 \cdot 6.3 .8$ ). $\mathrm{Ca}^{2+}$ ATPase activity was measured in the pellet, using a colorimetric method described by Desaiah et al. [34]. The pellet $(\sim 50 \mu \mathrm{g}$ mitochondrial protein) was incubated in the reaction medium of final volume $1 \mathrm{~mL}$. The specific activity of the enzyme is expressed as $\mu$ mole Pi released/mg protein/min.

2.5. Measurement of Lipid Peroxidation. The formation of lipid peroxides was measured in the homogenates of the whole liver. The formation of MDA, an end product of fatty acid peroxidation was measured spectrophotometrically at $532 \mathrm{~nm}$ by using a thiobarbituric acid reactive substance (TBARS) essentially by the method of Genet et al. [35] Results are expressed as nmole of MDA formed/mg protein.

2.6. Lipofuscin Content. The extraction of lipofuscin and measurement of its fluorescence were essentially as described by Tappel et al. [36]. Using a primary filter $(366 \mathrm{~nm})$ for excitation and a secondary filter for emission (485 $\mathrm{nm})$ fluorescence measurements were carried out using a SLM 4800 model spectroflourometer. Quinine sulphate $(0.1 \mu \mathrm{g} / \mathrm{mL})$ in $0.05 \mathrm{M} \mathrm{H}_{2} \mathrm{SO}_{4}$ was used as a standard. The results were expressed as percentage fluorescence of control from $1 \mathrm{~mL}$ of homogenate $(\mathrm{w} / \mathrm{v})$.

2.7. Membrane Fluidity. The pellets were labelled with 1,6diphenyl-1, 3, 5-hexatriene (DPH), a fluorescent probe by incubating equal volume of the suspension containing $100 \mu \mathrm{g} \cdot \mathrm{mL}^{-1}$ of protein in phosphate buffer and $2 \mu \mathrm{M} \mathrm{DPH}$ suspension in the same buffer. Excitation and emission wavelengths were, respectively, 365 and $428 \mathrm{~nm}$. Polarization 
$(P)$ and anisotropy $(r)$ measurements were carried out on a model SLM 4800 polarization spectroflourometer as described by Kumar et al. [29].

2.8. Protein Estimation. Protein was estimated in subcellular fractions by the method of Bradford [37] using bovine serum albumin (BSA) as standard.

2.9. Statistical Analysis. Results were analyzed using Prism 5.0 (GraphPad, San Diego, Calif, USA). The values are expressed as mean \pm SEM of 4-6 separate values. The data were analyzed using one-way ANOVA followed by TurkeyKramer multiple comparison test to determine the statistical significance. The significance was calculated by comparing the age-matched controls with experimental groups.

2.10. Chemicals. All purified enzymes, coenzymes, substrates, standards, and buffers were from Sigma Chemicals Company, USA. All other chemicals were of analytical grade and purchased from SRL and Qualigens, India.

\section{Results}

3.1. Effect of E2 on General Physiological Parameters in Aging. An increase in body weight throughout the study was observed with aging in all the groups. The body weights of the aging animals increased significantly $(P<0.05)$ at 12 and $(P<0.001)$ in 24 months when compared with 3 -month control rats. There was a significant decrease $(P<0.05)$ with E2 treatment in 24-month age groups when compared with respective controls. There were no significant changes in body weight at 12- and 24-month E2 treatment groups when compared with 3-month control rats. The protein content in the whole homogenates, supernatant, and pellet fractions did not show significant changes with aging and E2 treatment. Results are shown in the Table 1.

3.2. Effect of E2 on Antioxidant Status in Aging. Changes in the activities of SOD and GST in cytosolic fractions in liver of 3, 12, and 24-month control and E2-treated aging female rats are summarized in Figure 1. With aging there was a decrease in SOD activity compared to 3-month control animals. In 24 -month control group a significant $(P<0.01)$ decrease was seen in SOD activity when compared with 3 -month controls. Treatment of E2 to aging animals increased SOD activity in 12 and 24 months, when compared with respective age-matched controls. There was no significant change in SOD activity at 12- and 24-month E2 treatment groups when compared with 3-month controls.

With aging there was a decrease in GST activity as compared to 3-month control animals. In 24 months there was a significant $(P<0.05)$ decrease in GST activity when compared with 3-month controls. When compared with respective age control group, an increased GST activity at 12- and 24-month E2-treated animals was seen. Treatment with $\mathrm{E} 2$ to aging rats restored the antioxidant enzyme activity nearly to 3-month controls. There was no significant change in GST activity at 12- and 24-month E2 treatment groups when compared with 3-month control rats.

3.3. Effect of E2 on Membrane-Linked ATPases in Aging. Changes in the activities of $\mathrm{Na}^{+} \mathrm{K}^{+}$ATPase and $\mathrm{Ca}^{2+}$ ATPase in pellet fractions of 3,12, and 24-month control and E2-treated aging female rats are summarized in Figure 2. With aging there was a decrease in $\mathrm{Na}^{+} \mathrm{K}^{+}$ATPase activity as compared to 3-month controls. In 12- and 24-month control group, there was a significant $(P<0.05)$ and $(P<$ 0.001) decrease in $\mathrm{Na}^{+} \mathrm{K}^{+}$ATPase activity when compared with 3-month controls, respectively. When compared with respective age controls group, there was no significant changes in 12-month E2-treated animals. In 24-month aged rats $\mathrm{Na}^{+} \mathrm{K}^{+}$ATPase activity increased significant after the E2 treatments $(P<0.001)$ when compared with respective agematched controls. There was no significant change in $\mathrm{Na}^{+} \mathrm{K}^{+}$ ATPase activity at 12- and 24-month E2 treatment groups when compared with 3-month control rats.

With aging there was a decrease in $\mathrm{Ca}^{2+}$ ATPase activity as compared to 3-month control animals. In 24 months there was a significant $(P<0.001)$ decrease in $\mathrm{Ca}^{2+}$ ATPase activity when compared with 3-month controls. When compared with respective age controls, there was no significant change in 12-month E2-treated animals. In 24-month aged rats $\mathrm{Ca}^{2+}$ ATPase activity increased after the E2 treatments $(P<$ $0.01)$ as compared to age-matched controls. There was no significant change in $\mathrm{Ca}^{2+}$ ATPase activity at 12- and 24month E2 treatment groups when compared with 3-month rats. Treatment with $\mathrm{E} 2$ in aging rats restored the membranelinked ATPases activities nearly to 3-month controls.

3.4. Effect of E2 on Membrane Lipid Peroxidation in Aging. Lipid peroxidation was measured as the formation of MDA in whole homogenates of aging rat liver from control and E2-treated aging animals. With aging there was significant increase $(P<0.001)$ in MDA levels at 12 - and 24-month age groups as compared to the 3-month control animals. For E2 treatment, to 12 and 24 months old, the MDA levels decreased significantly $(P<0.001)$ at 12 months and $(P<$ 0.001 ) in 24-month rats, respectively, when compared with age-matched controls. There was a significant $(P<0.001)$ change in MDA levels at 12- and 24-month E2 treatment groups when compared with 3 months. Administration of E2 restored the MDA levels nearly to 3-month controls. Results are shown in Figure 3(a).

3.5. Effect of E2 on Lipofuscin Content in Aging. Lipofuscin content was measured in whole homogenates of aging rat liver of control and E2-treated aging animals. With age there was significant increase $(P<0.001)$ in lipofuscin content at 24 months as compared to the 3-month control animals. Administration of $\mathrm{E} 2$ treatment decreased lipofuscin content in 24 months, respectively, as compared to the age-matched controls $(P<0.01)$. There was no significant change in lipofuscin content at 12- and 24-month E2 treatment groups when compared with 3-month control rats. Results are shown in Figure 3(b). 
TABLE 1: Body weight and protein concentration of 3, 12, and 24 months of control (C) and estradiol- (E2-) treated aging female rats.

\begin{tabular}{|c|c|c|c|c|}
\hline \multirow{2}{*}{ Age/treatment } & \multirow{2}{*}{ Body wt. (g) } & \multicolumn{3}{|c|}{ Protein content $(\mathrm{mg} / \mathrm{g})$} \\
\hline & & Whole homogenate & Supernatant & Mitochondria \\
\hline \multicolumn{5}{|l|}{3 months } \\
\hline $\mathrm{C}$ & $218 \pm 23$ & $168 \pm 17.3$ & $129 \pm 9.3$ & $17.9 \pm 1.6$ \\
\hline \multicolumn{5}{|l|}{12 months } \\
\hline $\mathrm{C}$ & $330 \pm 18^{*}$ & $160 \pm 18.5$ & $110 \pm 4.9$ & $19.5 \pm 2.1$ \\
\hline E2 & $243 \pm 27$ & $164 \pm 7.9$ & $118 \pm 8.6$ & $20.8 \pm 2.7$ \\
\hline \multicolumn{5}{|l|}{24 months } \\
\hline $\mathrm{C}$ & $425 \pm 36^{\$}$ & $156 \pm 13.6$ & $108 \pm 7.4$ & $17.2 \pm 1.4$ \\
\hline E2 & $292 \pm 28^{c}$ & $162 \pm 8.3$ & $120 \pm 4.5$ & $18.6 \pm 1.2$ \\
\hline
\end{tabular}

Each value is a mean \pm SEM of five or more separate values from two to three experiments. The comparisons of experimental values are with the control values. Statistical significance: ${ }^{\mathrm{c}} P<0.05$ comparing age-matched controls versus E2 treatment and ${ }^{\$} P<0.001,{ }^{*} P<0.05$ versus 3 months.

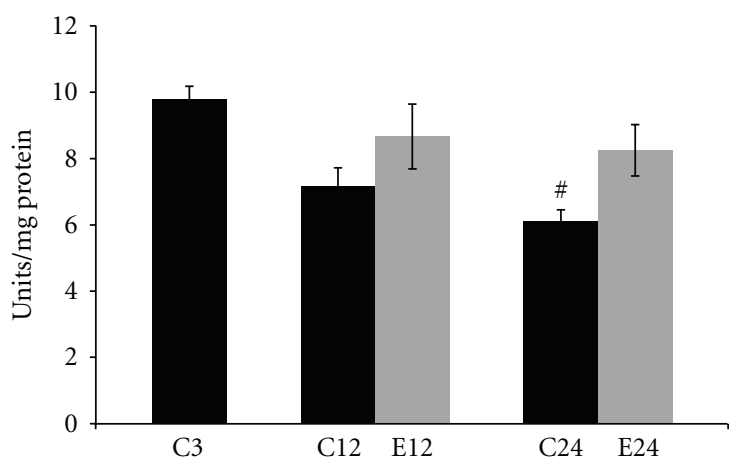

(a)

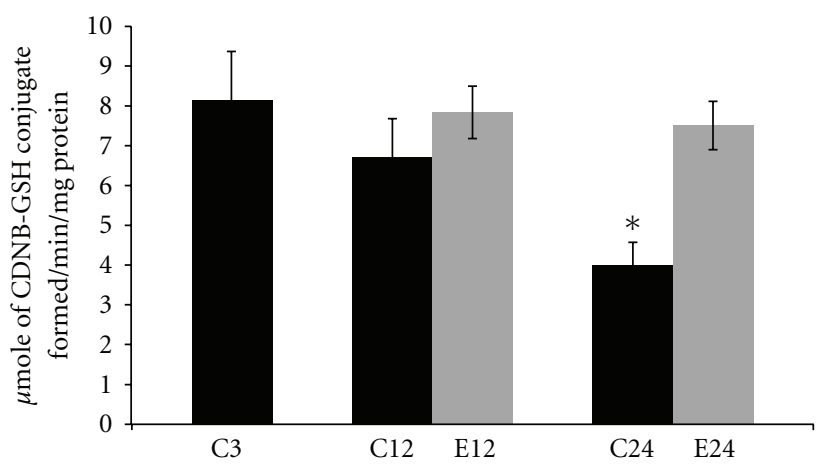

(b)

FIGURE 1: Changes in the activities of antioxidant enzymes (a) superoxide dismutase (SOD) and (b) glutathione S-transferase (GST) in liver supernatant fraction of 3, 12, and 24 months of control (C) and estradiol- (E2-) treated aging female rats. Each value is a mean \pm SEM of five or more separate values from two to three experiments. The comparisons of experimental values are with the control values. Statistical significance: ${ }^{\#} P<0.01,{ }^{*} P<0.05$ versus 3 months.

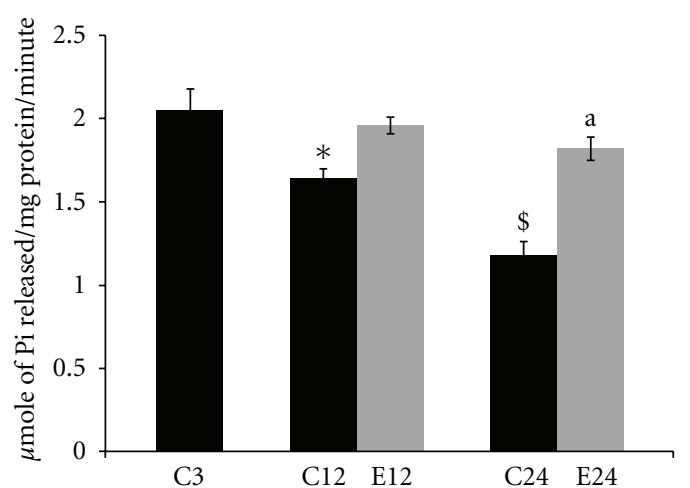

(a)

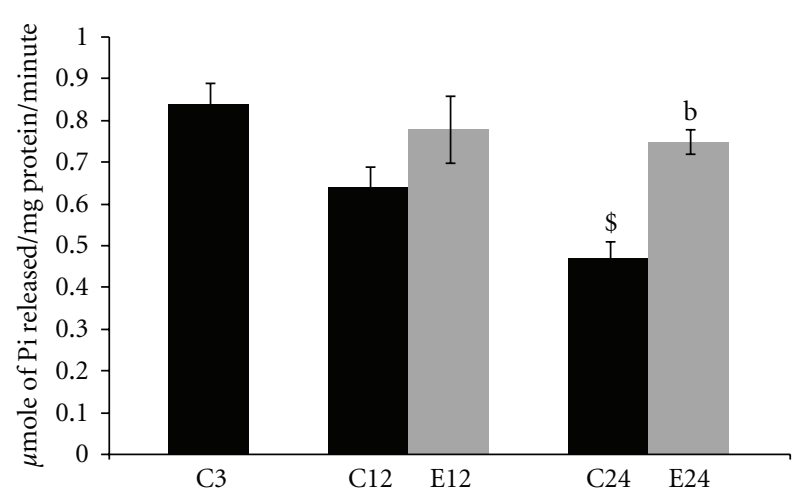

(b)

FIgURE 2: Changes in the activities of membrane-linked ATPase (a) $\mathrm{Na}^{+} \mathrm{K}^{+}$ATPase and (b) $\mathrm{Ca}^{2+}$ ATPase in liver mitochondria of 3, 12, and 24 months of control (C) and estradiol- (E2-) treated aging female rats. Each value is a mean \pm SEM of five or more separate values from two to three experiments. The comparisons of experimental values are with the control values. Statistical significance: ${ }^{\text {a }} P<0.001,{ }^{b} P<0.01$ comparing age-matched controls versus E2 treatment and ${ }^{\$} P<0.001,{ }^{*} P<0.05$ versus 3 months.

3.6. Effect of E2 on Membrane Fluidity in Aging. The DPH fluorescence polarization $(P)$ and anisotropy $(r)$ values were found to increase $(P<0.001)$ in the liver pellet with aging, reflecting a decrease in the probe mobility and an increase in membrane structural order or a decrease in membrane fluidity. The membrane fluidity is inversely related to the anisotropy and polarization parameters. The changes in fluidity measured in control and E2-treated animals of different age groups showed significant decrease in fluidity with increasing age from 3 months to 24 months. Twelve and 


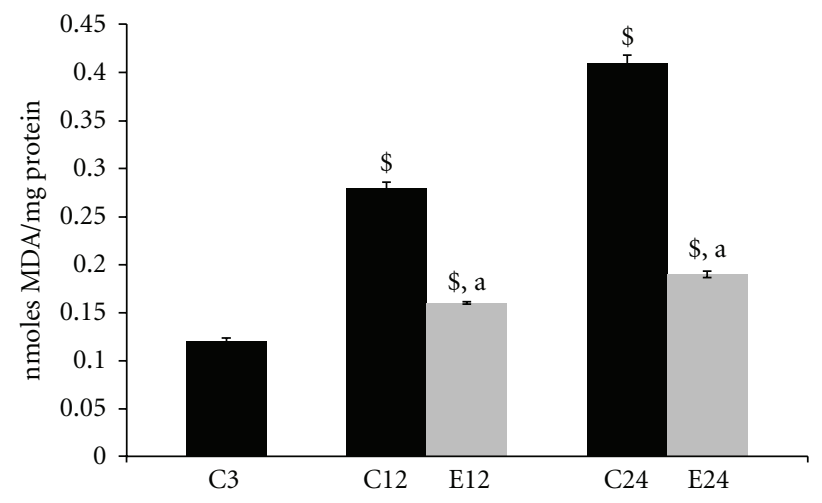

(a)

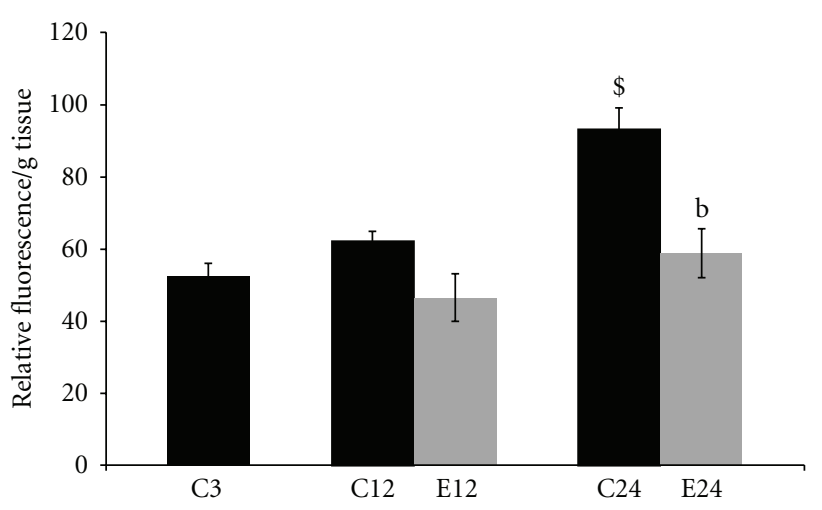

(b)

FIGURE 3: Changes in lipid peroxidation (a) and lipofuscin content (b) in liver of 3, 12, and 24 months of control (C) and estradiol- (E2-) treated aging female rats. Each value is a mean \pm SEM of five or more separate values from two to three experiments. The comparisons of experimental values are with the control values. Statistical significance: ${ }^{\mathrm{a}} P<0.001,{ }^{\mathrm{b}} P<0.01$ comparing age-matched controls versus E2 treatment and ${ }^{\$} P<0.001$ versus 3 months.

24-month E2-treated groups elicited a significant $(P<0.01)$ and $(P<0.001)$ decrease in anisotropy as compared to the respective controls. There was a significant $(P<0.01)$ increase in polarization values at 12 -month E2 treatment groups when compared with 3-month control rats. Results are presented in Table 2 .

\section{Discussion}

Free radical production and oxidative stress are known to increase during aging and may contribute to the oxidative damage, which plays an important role in the aging process [1]. The impairment of liver metabolism and its gross architecture, during aging, finally leads to liver cell death [9]. Agerelated changes in liver may have important implications for systemic immune responses and hepatic function [38]. Liver tissue has the highest population of macrophages in the body and therefore has a great potential for producing local and/or systemic inflammatory responses [39]. Recently Kireev et al. [40] had demonstrated that aging produced significantly increased levels of the proinflammatory cytokines TNFa, IL-1b, and IL-6, whereas the anti-inflammatory IL-10 showed a decrease in liver homogenates of old female rats. Administration of the E2 treatment inhibits the induction of proinflammatory cytokines and iNOS, decreasing the levels of oxidative stress markers [41].

The present study elucidated the antiaging and protective potential of E2 treatment on activities of membrane-linked ATPases $\left(\mathrm{Na}^{+} \mathrm{K}^{+}\right.$ATPase, $\mathrm{Ca}^{2+}$ ATPase), antioxidant enzymes (SOD, GST), lipid peroxidation levels, lipofuscin content, and membrane fluidity in the livers of aging female rats. Earlier data from our laboratory showed decreased levels of E2 at 12 and 24 months as compared to the 3 -month cyclic rats [10]. The body weight of the female rats increased with age, primarily due to the increased amount of adipose tissue in the aged rats. A significant decrease in body weight was found with E2 treatment, which could be due to the antiobesity action of E2 [6]. The liver weights were also increased with
TABLE 2: Changes in polarization and anisotropy measurements in liver of 3, 12, and 24 months of control (C) and estradiol- (E2-) treated aging female rats.

\begin{tabular}{lcc}
\hline \multirow{2}{*}{ Age/treatment } & \multicolumn{2}{c}{ Membrane fluidity } \\
& Polarization $(P)$ & Anisotropy $(r)$ \\
\hline 3 months & $0.170 \pm 0.002$ & $0.157 \pm 0.002$ \\
C & $0.208 \pm 0.003^{\$}$ & $0.195 \pm 0.003^{\$}$ \\
\hline 12 months & $0.172 \pm 0.004^{\mathrm{b}}$ \\
C & $0.195 \pm 0.002^{\#}$ & \\
E2 & & $0.203 \pm 0.005^{\$}$ \\
\hline 24 months & $0.224 \pm 0.008^{\$}$ & $0.161 \pm 0.008^{\mathrm{a}}$ \\
C & $0.179 \pm 0.002^{\mathrm{a}}$ & \\
E2 &
\end{tabular}

Each value is a mean \pm SEM of five or more separate values from two to three experiments. The comparisons of experimental values are with the control values. Statistical significance: ${ }^{\mathrm{a}} P<0.001,{ }^{\mathrm{b}} P<0.01$ comparing age matched controls versus E2 treatment and ${ }^{\$} P<0.001,{ }^{\#} P<0.01$ versus 3 months.

age when compared to control (3 months old) animals. After the E2 treatment the liver weight was increased. This increase may be due to increased level of protein content in the liver (data not shown). Protein content of the hormone-treated rats which increased significantly in liver may be due to decreased protein catabolism and increased protein synthesis and also due to decreased gluconeogenesis $[6,25]$.

The present study reiterates the age-related decline in activities of antioxidant enzymes in aging liver. Present data showed that SOD activity decreased significantly in liver of aged animals, agreeing with earlier reports $[10,16,42]$; results also show a parallel decline in GST activity with aging $[20,43]$. E2 treatment to aging rats, which restored SOD and GST activities, may be due to a decrease in free radicals generation by E2 and increased in antioxidant defenses [5, 44]. Kireev et al. [45] showed that ovariectomy decreased GST activity, increased mitochondrial damage in liver, and 
these changes were improved by E2 administration. Several studies by the group of Viña et al. [46, 47] showed the role of E2 in different organs, including liver. Estrogen administration regulates the expression of antioxidant, longevityrelated genes, and consequently oxidant levels in aging animals. Estrogens modulate the antioxidant gene expression via the transcription factor as NF-kB. Estrogens upregulate mitochondrial antioxidant genes in females, leading to a lower mitochondrial oxygen radical generation, and help in longer longevity of females versus males in Wistar rats [48].

$\mathrm{Na}^{+} \mathrm{K}^{+}$ATPase activity decreased significantly in liver mitochondria of aged animals when compared to 3-month control animals. This is in agreement with earlier studies $[20,42]$. The decrease in $\mathrm{Na}^{+} \mathrm{K}^{+}$ATPase could be due to increased oxidative stress and ROS formation with aging leading to increased lipid peroxidation and further damage to membrane structure. E2 treatment to aging animals restored the $\mathrm{Na}^{+} \mathrm{K}^{+}$ATPase activity to almost control levels. E2 may be acting as a radical scavengers by decreasing ROS in aged rats and maintain the fluidity $[4,49]$. In the present study, $\mathrm{Ca}^{2+}$ ATPase activity decreased in liver mitochondria of aging rats when compared with 3-month controls. The decreased $\mathrm{Ca}^{2+}$ ATPase activity may lead to increase in intracellular $\mathrm{Ca}^{2+}$ levels, alter the cellular fluidity, and eventually result in cell death [36]. E2 treatment to aging rats prevented the decreased $\mathrm{Ca}^{2+}$ ATPase activity, also decreased oxidative stress and ROS in aged rats, and restored the membrane fluidity. E2 increased membrane-linked ATPases; perhaps E2 acts as an endogenous modulator of ATPases and attenuates the impact of age-related $\mathrm{Ca}^{2+}$ dyshomeostasis $[10,49]$.

With aging there is significant increase in lipid peroxidation at 12- and 24-month old rats as compared to 3month controls. Ample evidence showed that peroxidative damage to lipid and protein occurs with the aging process and that the products of these reactions accumulate with age $[2,27,28,50,51]$. Aging rats treated with E2 reversed the MDA levels to almost normal levels in the liver, suggesting its anti-lipidperoxidative abilities $[8,49]$. Lipofuscin is a peroxidation product, and its formation appears to be integrative and proportional to the occurrence of lipid peroxidation. An age-related increase in lipid peroxidation has been shown to correlate with the gross level of lipofuscin [49]. E2 treatment to aging animals showed a decrease in lipofuscin content in liver $[4,29,52]$.

Present results showed the age-dependent reduction of membrane fluidity $[29,53]$. The treatment of aging animals with E2 reverted the membrane fluidity to normal level as compared to untreated age-matched controls. E2 treatment decreased free radicals formation and decreased lipid peroxidation levels, which further improves membrane fluidity [54]. Estrogen has been known to function as a radical scavenger inhibiting lipid peroxidation in vivo and in vitro $[2,10,29]$.

E2's beneficial effects seemed to arise from its biochemical and metabolic effects as an antioxidant and protective role. It can therefore be concluded that age-related effects by estrogen hold great promise for improving the clinical management of selected age-related diseases and metabolic syndrome.

\section{Abbreviations}

E2: $\quad 17-\beta$-estradiol,

GST: glutathione S-transferases,

HRT: hormone replacement therapy,

MDA: Malondialdehyde,

ROS: reactive oxygen species,

SOD: superoxide dismutase.

\section{Acknowledgment}

The author Pardeep Kumar is grateful to the financial support from Council of Scientific and Industrial Research in the form of Junior and Senior Research Fellowship. Financial grant from Indian Council of Medical Research and University Grant Commission, New Delhi, India in the form of projects is acknowledged. The authors wish to express their appreciation to Professor P. McLean, University College London Medical School, London for her invaluable suggestions.

\section{References}

[1] D. Harman, "Free radical theory of aging," Mutation Research, vol. 275, no. 3-6, pp. 257-266, 1992.

[2] N. Z. Baquer, A. Taha, P. Kumar et al., "A metabolic and functional overview of brain aging linked to neurological disorders," Biogerontology, vol. 10, no. 4, pp. 377-413, 2009.

[3] Y. Hou, H. Wei, Y. Luo, and G. Liu, "Modulating expression of brain heat shock proteins by estrogen in ovariectomized mice model of aging," Experimental Gerontology, vol. 45, no. 5, pp. 323-330, 2010.

[4] K. Hamden, S. Carreau, F. Ellouz, H. Masmoudi, and A. El Feki, "Protective effect of $17 \beta$-estradiol on oxidative stress and liver dysfunction in aged male rats," Journal of Physiology and Biochemistry, vol. 63, no. 3, pp. 195-202, 2007.

[5] V. W. Henderson, "Action of estrogens in the aging brain: dementia and cognitive aging," Biochimica et Biophysica Acta, vol. 1800, no. 10, pp. 1077-1083, 2010.

[6] K. Moorthy, U. C. S. Yadav, M. R. Siddiqui, D. Sharma, S. F. Basir, and N. Z. Baquer, "Effect of estradiol and progesterone treatment on carbohydrate metabolizing enzymes in tissues of aging female rats," Biogerontology, vol. 5, no. 4, pp. 249-259, 2004.

[7] G. Lu, I. Shimizu, X. Cui et al., "Antioxidant and antiapoptotic activities of idoxifene and estradiol in hepatic fibrosis in rats," Life Sciences, vol. 74, no. 7, pp. 897-907, 2004.

[8] K. Hamden, S. Carreau, F. Ayadi, H. Masmoudi, and A. E. Feki, "Inhibitory effect of estrogens, phytoestrogens, and caloric restriction on oxidative stress and hepato-toxicity in aged rats," Biomedical and Environmental Sciences, vol. 22, no. 5, pp. 381-387, 2009.

[9] N. Gagliano, F. Grizzi, and G. Annoni, "Mechanisms of aging and liver functions," Digestive Diseases, vol. 25, no. 2, pp. 118123, 2007.

[10] K. Moorthy, D. Sharma, S. F. Basir, and N. Z. Baquer, "Administration of estradiol and progesterone modulate the activities of antioxidant enzyme and aminotransferases in naturally menopausal rats," Experimental Gerontology, vol. 40, no. 4, pp. 295-302, 2005.

[11] N. P. Sudheesh, T. A. Ajith, V. Ramnath, and K. K. Janardhanan, "Therapeutic potential of Ganoderma lucidum 
(Fr.) P. Karst. against the declined antioxidant status in the mitochondria of post-mitotic tissues of aged mice," Clinical Nutrition, vol. 29, no. 3, pp. 406-412, 2010.

[12] S. P. Singh, A. J. Janecki, S. K. Srivastava et al., "Membrane association of glutathione S-transferase mGSTA4-4, an enzyme that metabolizes lipid peroxidation products," Journal of Biological Chemistry, vol. 277, no. 6, pp. 4232-4239, 2002.

[13] M. C. Carrillo, S. Kanai, K. Miyasaka, and K. Kitani, "A protein free diet uncovers the potential age-difference in the hepatic detoxifying system, glutathione S-transferase, in female mice," Mechanisms of Ageing and Development, vol. 123, no. 12, pp. 1617-1623, 2002.

[14] E. Martínez-Lara, E. Siles, R. Hernández et al., "Glutathione $S$-transferase isoenzymatic response to aging in rat cerebral cortex and cerebellum," Neurobiology of Aging, vol. 24, no. 3, pp. 501-509, 2003.

[15] L. H. Chen, N. Hu, and D. L. Snyder, "Effects of age and dietary restriction on liver glutathione transferase activities in Lobund-Wistar rats," Archives of Gerontology and Geriatrics, vol. 18, no. 3, pp. 191-205, 1994.

[16] F. Mármol, J. Sánchez, D. López et al., "Role of oxidative stress and adenosine nucleotides in the liver of aging rats," Physiological Research, vol. 59, no. 4, pp. 553-560, 2010.

[17] K. Kitani, "Drugs and the ageing liver," Life Chemistry Reports, vol. 6, no. 2, pp. 143-230, 1988.

[18] V. V. Frolkis, A. L. Kobzar, and O. V. Sokolova, "Effects of partial hepatectomy on the plasma membrane status and the invertor mechanism of the hepatocyte Na,K-ATPase activity regulation in rats of various age," Aging-Clinical and Experimental Research, vol. 11, no. 2, pp. 130-134, 1999.

[19] V. Haynes, N. J. Traaseth, S. Elfering, Y. Fujisawa, and C. Giulivi, "Nitration of specific tyrosines in FoF1 ATP synthase and activity loss in aging," American Journal of PhysiologyEndocrinology and Metabolism, vol. 298, no. 5, pp. E978-E987, 2010.

[20] J. Kaur, D. Sharma, and R. Singh, "Acetyl-L-carnitine enhances $\mathrm{Na}^{+}, \mathrm{K}^{+}$-ATPase glutathione-S-transferase and multiple unit activity and reduces lipid peroxidation and lipofuscin concentration in aged rat brain regions," Neuroscience Letters, vol. 301, no. 1, pp. 1-4, 2001.

[21] I. Grattagliano, L. Bonfrate, C. V. Diogo, H. H. Wang, D. Q. H. Wang, and P. Portincasa, "Biochemical mechanisms in druginduced liver injury: certainties and doubts," World Journal of Gastroenterology, vol. 15, no. 39, pp. 4865-4876, 2009.

[22] I. Tamburini, M. F. Quartacci, R. Izzo, and E. Bergamini, "Effects of dietary restriction on age-related changes in the phospholipid fatty acid composition of various rat tissues," Aging-Clinical and Experimental Research, vol. 16, no. 6, pp. 425-431, 2004.

[23] H. Berrougui and A. Khalil, "Age-associated decrease of highdensity lipoprotein-mediated reverse cholesterol transport activity," Rejuvenation Research, vol. 12, no. 2, pp. 117-126, 2009.

[24] H. Esterbauer, R. J. Schaur, and H. Zollner, "Chemistry and biochemistry of 4-hydroxynonenal, malonaldehyde and related aldehydes," Free Radical Biology and Medicine, vol. 11, no. 1, pp. 81-128, 1991.

[25] K. Moorthy, U. C. S. Yadav, M. R. Siddiqui et al., "Effect of hormone replacement therapy in normalizing age related neuronal markers in different age groups of naturally menopausal rats," Biogerontology, vol. 6, no. 5, pp. 345-356, 2005.

[26] R. Mahesh, S. Bhuvana, and V. M. H. Begum, "Effect of Terminalia chebula aqueous extract on oxidative stress and antioxidant status in the liver and kidney of young and aged rats," Cell Biochemistry and Function, vol. 27, no. 6, pp. 358363, 2009.

[27] P. Kumar, A. Taha, D. Sharma, R. K. Kale, and N. Z. Baquer, "Effect of dehydroepiandrosterone (DHEA) onmonoamine oxidase activity, lipid peroxidation and lipofuscin accumulation in aging rat brain regions," Biogerontology, vol. 9, no. 4, pp. 235-246, 2008.

[28] P. Kumar, A. Taha, D. Sharma, R. K. Kale, and N. Z. Baquer, "Effect of dehydroepiandrosterone (DHEA) on monoamine oxidase activity, lipid peroxidation and lipofuscin accumulation in aging rat brain regions," Biogerontology, vol. 9, no. 4, pp. 283-284, 2008.

[29] P. Kumar, A. Taha, R. K. Kale, S. M. Cowsik, and N. Z. Baquer, "Physiological and biochemical effects of $17 \beta$ estradiol in aging female rat brain,” Experimental Gerontology, vol. 46, no. 7, pp. 597-605, 2011.

[30] M. R. Siddiqui, A. Taha, K. Moorthy, M. E. Hussain, S. F. Basir, and N. Z. Baquer, "Amelioration of altered antioxidant status and membrane linked functions by vanadium and Trigonella in alloxan diabetic rat brains," Journal of Biosciences, vol. 30, no. 4, pp. 483-490, 2005.

[31] S. Marklund and G. Marklund, "Involvement of the super anion radicals in the autoxidation of pyrogollol and a convenient assay for superoxide dismutase," European Journal of Biochemistry, vol. 47, pp. 469-474, 1974.

[32] B. L. Gupta, A. Preet, and N. Z. Baquer, "Protective effects of sodium orthovanadate in diabetic reticulocytes and ageing red blood cells of Wistar rats," Journal of Biosciences, vol. 29, no. 1, pp. 73-79, 2004.

[33] C. S. K. Mayanil, S. M. I. Kazmi, and N. Z. Baquer, " $\mathrm{Na}^{+}, \mathrm{K}^{+}-$ ATPase and $\mathrm{Mg}^{2+}$-ATPase activities in different regions of rat brain during alloxan diabetes," Journal of Neurochemistry, vol. 39, no. 4, pp. 903-908, 1982.

[34] D. Desaiah, C. S. Chetty, and K. S. Prasada Rao, "Chlordecone inhibition of calmodulin activated calcium ATPase in rat brain synaptosomes," Journal of Toxicology and Environmental Health, vol. 16, no. 2, pp. 189-195, 1985.

[35] S. Genet, R. K. Kale, and N. Z. Baquer, "Alterations in antioxidant enzymes and oxidative damage in experimental diabetic rat tissues: effect of vanadate and fenugreek (Trigonella foenum graecum)," Molecular and Cellular Biochemistry, vol. 236, no. 1-2, pp. 7-12, 2002.

[36] A. Tappel, B. Fletcher, and D. Deamer, "Effect of antioxidants and nutrients on lipid peroxidation fluorescent products and aging parameters in the mouse," Journals of Gerontology, vol. 28, no. 4, pp. 415-424, 1973.

[37] M. M. Bradford, "A rapid and sensitive method for the quantitation of microgram quantities of protein utilizing the principle of protein dye binding," Analytical Biochemistry, vol. 72, no. 1-2, pp. 248-254, 1976.

[38] S. N. Hilmer, V. C. Cogger, and D. G. Le Couteur, "Basal activity of kupffer cells increases with old age," Journals of Gerontology-Series A Biological Sciences and Medical Sciences, vol. 62, no. 9, pp. 973-978, 2007.

[39] A. Ayala, M. M. Perrin, W. Ertel, and I. H. Chaudry, "Differential effects of hemorrhage on kupffer cells: decreased antigen presentation despite increased inflammatory cytokine (IL-1, IL-6 and TNF) release," Cytokine, vol. 4, no. 1, pp. 66$75,1992$.

[40] R. A. Kireev, A. C. F. Tresguerres, C. Garcia et al., "Hormonal regulation of pro-inflammatory and lipid peroxidation processes in liver of old ovariectomizedfemale rats," Biogerontology, vol. 11, no. 2, pp. 229-243, 2010. 
[41] G. Sener, S. Arbak, P. Kurtaran, N. Gedik, and B. C. Yegen, "Estrogen protects the liver and intestines against sepsisinduced injury in rats," Journal of Surgical Research, vol. 128, no. 1, pp. 70-78, 2005.

[42] A. K. Mantha, K. Moorthy, S. M. Cowsik, and N. Z. Baquer, "Membrane associated functions of neurokinin B (NKB) on $\mathrm{A} \beta$ (25-35) induced toxicity in aging rat brain synaptosomes," Biogerontology, vol. 7, no. 1, pp. 19-33, 2006.

[43] K. D. Tew and Z. Ronai, "GST function in drug and stress response," Drug Resistance Updates, vol. 2, no. 3, pp. 143-147, 1999.

[44] M. Ulas and M. Cay, "The effects of $17 \beta$-estradiol and vitamin e treatments on oxidative stress and antioxidant levels in brain cortex of diabetic ovariectomized rats," Acta Physiologica Hungarica, vol. 97, no. 2, pp. 208-215, 2010.

[45] R. A. Kireev, A. F. Tresguerres, E. Vara, C. Ariznavarreta, and J. A. F. Tresguerres, "Effect of chronic treatments with GH, melatonin, estrogens, and phytoestrogens on oxidative stress parameters in liver from aged female rats," Biogerontology, vol. 8, no. 5, pp. 469-482, 2007.

[46] J. Viña, M. C. Gomez-Cabrera, and C. Borras, "Fostering antioxidant defences: up-regulation of antioxidant genes or antioxidant supplementation?" British Journal of Nutrition, vol. 98, supplement 1, pp. S36-S40, 2007.

[47] J. Viña, J. Sastre, F. V. Pallardó, J. Gambini, and C. Borrás, "Modulation of longevity-associated genes by estrogens or phytoestrogens," Biological Chemistry, vol. 389, no. 3, pp. 273277, 2008.

[48] J. Viña and C. Borrás, "Women live longer than men: understanding molecular mechanisms offers opportunities to intervene by using estrogenic compounds," Antioxidants and Redox Signaling, vol. 13, no. 3, pp. 269-278, 2010.

[49] I. Shimizu and S. Ito, "Protection of estrogens against the progression of chronic liver disease," Hepatology Research, vol. 37, no. 4, pp. 239-247, 2007.

[50] M. Hashimoto, M. H. Shahdat, T. Shimada et al., "Relationship between age-related increases in rat liver lipid peroxidation and bile canalicular plasma membrane fluidity," Experimental Gerontology, vol. 37, no. 1, pp. 89-97, 2001.

[51] X. Wang, Y. Liao, G. Li, D. Yin, and S. Sheng, "A comparative study of artificial ceroid/lipofuscin from different tissue materials of rats," Experimental Aging Research, vol. 34, no. 3, pp. 282-295, 2008.

[52] P. Kumar, R. K. Kale, P. McLean, and N. Z. Baquer, "Protective effects of $17 \beta$ estradiol on altered age related neuronal parameters in female rat brain," Neuroscience Letters, vol. 502, no. 1, pp. 56-60, 2011.

[53] H. Berrougui and A. Khalil, "Age-associated decrease of highdensity lipoprotein-mediated reverse cholesterol transport activity," Rejuvenation Research, vol. 12, no. 2, pp. 117-126, 2009.

[54] P. Kumar, R. K. Kale, and N. Z. Baquer, New Frontiers in Molecular Mechanisms of Neurological and Psychiatric Disorders, ISBN no. 97880-8886699, Jessenius Faculty of Medicine, Comenius University, Martin, Slovakia, 2011. 


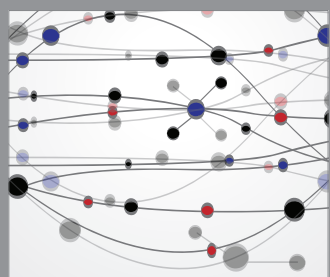

The Scientific World Journal
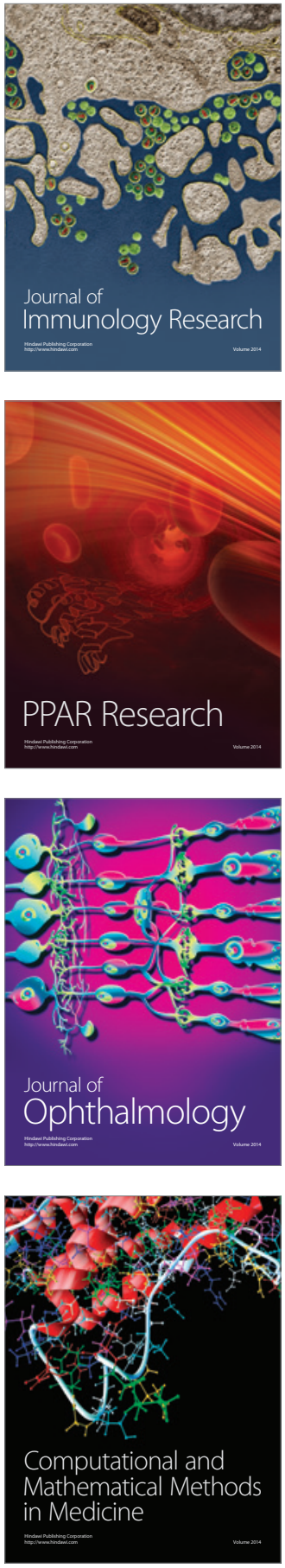

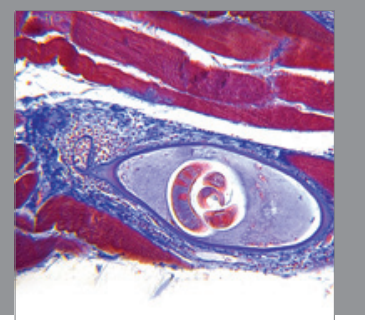

Gastroenterology

Research and Practice
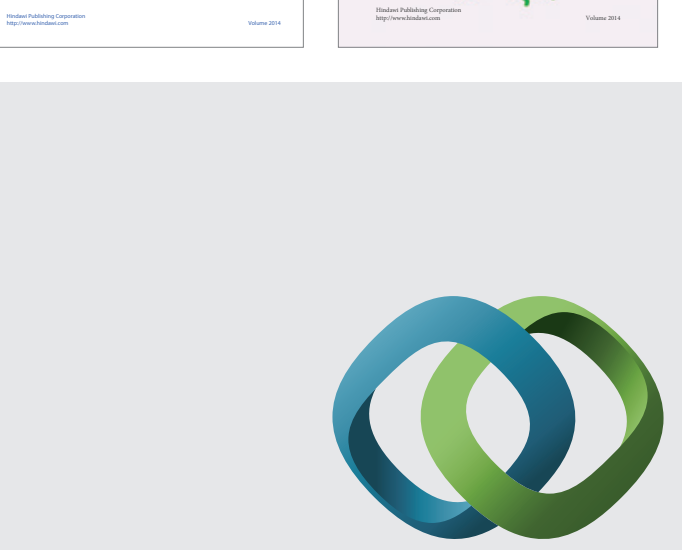

\section{Hindawi}

Submit your manuscripts at

http://www.hindawi.com
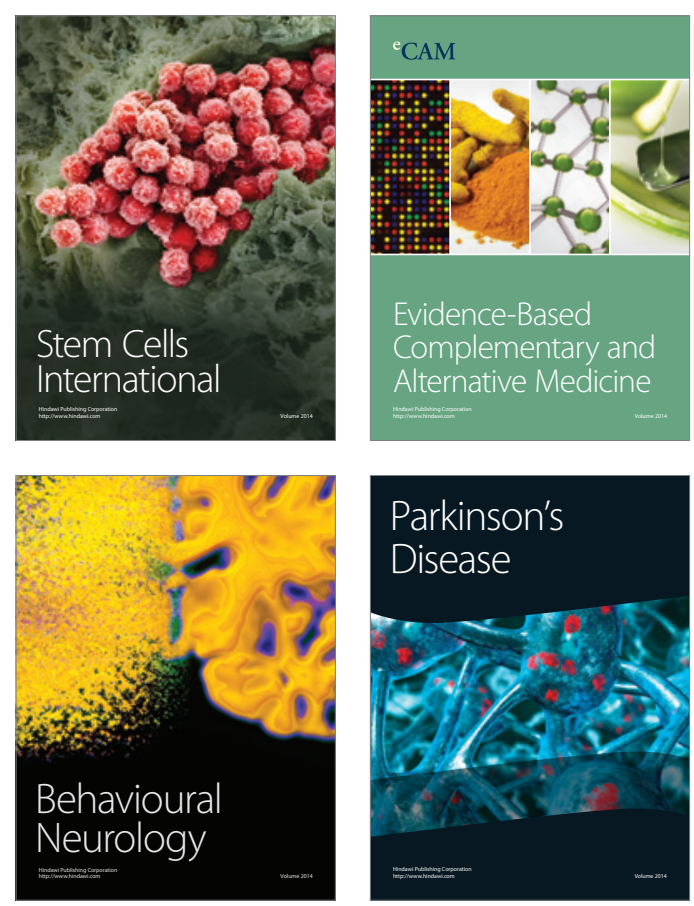

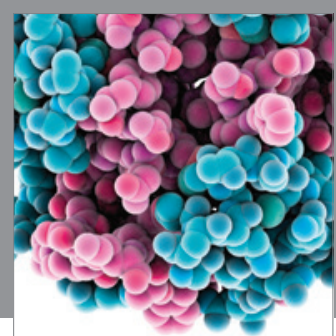

Journal of
Diabetes Research

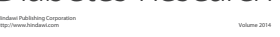

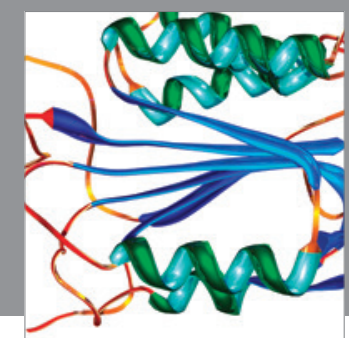

Disease Markers
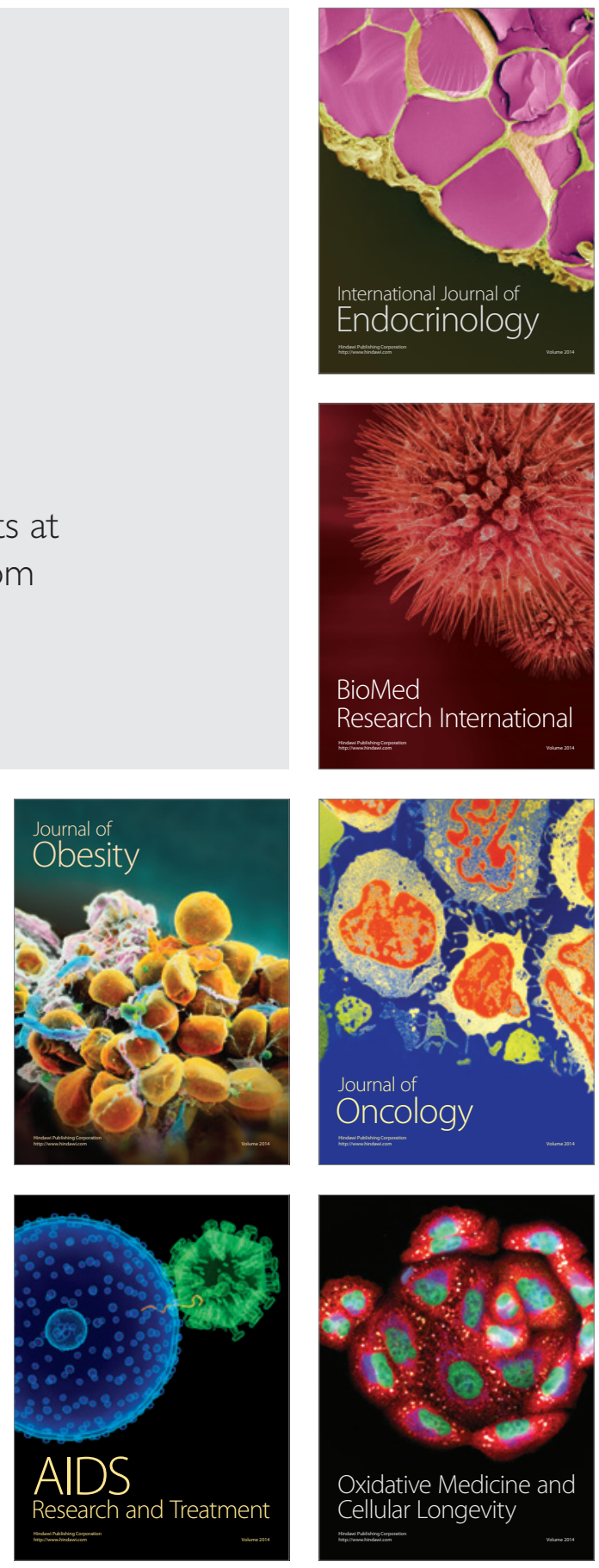